\title{
Concomitant Celiac Disease and Wheat Allergy: 2 Case Reports
}

\author{
Lombardi $\mathrm{C}^{1}$, Savi $\mathrm{E}^{2}$, Passalacqua $\mathrm{G}^{3}$ \\ ${ }^{1}$ Departmental Unit of Allergology, Clinical Immunology \& \\ Pneumology, Fondazione Poliambulanza, Brescia, Italy \\ ${ }^{2}$ Departimental Unit of Allergology, G.Da Saliceto Hospital, \\ Piacenza, Italy \\ ${ }^{3}$ Allergy and Respiratory Diseases, Policlinico San Martino- \\ University of Genoa, Genoa, Italy
} J Investig Allergol Clin Immunol 2019; Vol. 29(6): 454-456
doi: 10.18176/jiaci.0421

Key words: Celiac disease. Wheat flour allergy. Diagnosis. Molecular diagnosis. Autoimmune disease.

Palabras clave: Enfermedad celíaca. Alergia a la harina de trigo. Diagnóstico. Diagnóstico molecular. Enfermedad autoimmune.

Wheat flour (Triticum aestivum) is a major food source throughout the world. It is used in the manufacture of bread, pasta, and cereals. Wheat can cause various diseases, including IgE-mediated food allergy, wheat-dependent exercise-induced anaphylaxis, respiratory allergy (baker's asthma), celiac disease, and nonceliac gluten sensitivity. Wheat allergy is an IgE-mediated response to any of the proteins present in wheat, including gluten. Its prevalence varies depending on age and region from $0.4 \%$ to $4 \%$ [1]. Around $65 \%$ of children outgrow this allergy by the age of 12 months. Celiac disease is an autoimmune disorder with an aberrant response to gluten proteins (present in wheat, barley, and rye) with subsequent atrophy of intestinal villi, impaired intestinal absorption, and malnutrition. The symptoms of wheat allergy can range from mild to life-threatening and include skin rash, nausea, abdominal pain, vomiting/diarrhea, respiratory symptoms, and even anaphylaxis. Onset is usually within minutes, more rarely within 1-2 hours. A tentative diagnosis can be made using skin prick testing or a specific serum IgE assay. Nonetheless, the assessment of IgE with the whole wheat extract is poorly sensitive and specific owing to crossreactivity with other allergenic molecules. Wheat proteins are classified into albumins, salt-soluble globulins, and insoluble prolamins (gliadins and glutenins). Molecular tests can identify the presence of specific IgE against individual components: glutenins, gliadin, $\omega-5$ gliadin, $\alpha$-amylase inhibitors, lipid transfer proteins, and Tri a $14[2,3]$. We report what could be the first 2 cases of concomitant celiac disease and IgE-mediated allergy to wheat proteins.

The first patient was a 15-year-old girl who was diagnosed with celiac disease at the age of 6 years based on symptoms, positive antitransglutaminase IgA level (240 IU/mL, [normal value $<7 \mathrm{IU} / \mathrm{mL}$ ], Thermo Fisher Scientific), antiendomysial IgA (1:256), and duodenal biopsy findings. She remained on a gluten-free diet, with clinical benefits and normal immunological test results. She came to our emergency 
department with generalized urticaria, lip swelling, abdominal pain, diarrhea, vomiting, and respiratory distress $\left(\mathrm{PaO}_{2}\right.$, $89 \mathrm{mmHg}$ ). She promptly recovered after intravenous methylprednisolone and intramuscular epinephrine. Symptoms had occurred thirty minutes after eating flat bread during a party. No consumption of alcohol or medications could be documented. Tryptase serum levels were increased $(14 \mu \mathrm{g} / \mathrm{mL})$ during the acute phase, although they returned to normal $(7.4 \mu \mathrm{g} / \mathrm{mL})$ after 48 hours, thus supporting the diagnosis of anaphylaxis. IgE to wheat was $1.5 \mathrm{kU} / \mathrm{L}$, with gluten-specific $\mathrm{IgE}$ at $2.4 \mathrm{kU} / \mathrm{L}$. The molecular diagnosis revealed sensitization to gliadin (4.9 kU/L) and rTri a 19.0101 ( $\omega-5$ gliadin $)(5.6 \mathrm{kU} / \mathrm{L})$. Findings for Tri a 14 were negative. The skin prick test, which was performed 2 weeks after the episode, was positive for gliadin $(8 \mathrm{~mm})$ (ALK-Abelló) but negative for the whole wheat extract. We deduced that the anaphylactic reaction was elicited by $\omega-5$ gliadin. The detailed clinical history revealed that, after years following a strict diet the patient started to eat wheat occasionally. The occasional consumption of wheatcontaining food after a long period with a gluten-free diet may have induced sensitization to $\omega-5$ gliadin. The patient was again instructed to avoid the culprit allergens and received the epinephrine auto-injector. Nevertheless, she continued to experience wheat-induced anaphylaxis. No exercise-induced condition was documented.

The second patient was a 54-year-old woman who was first diagnosed with celiac disease at the age of 26 . She followed a gluten-free diet, although her clinical history revealed episodes of anaphylaxis after the ingestion of wheat-containing foods, with raised serum tryptase $(15.8 \mathrm{ng} / \mathrm{mL}$ [baseline, $4.3 \mathrm{ng} / \mathrm{mL}])$. She was referred to our emergency department with hypotension, generalized urticaria, lip swelling, abdominal pain, diarrhea/ vomiting, and dyspnea. The episode was rapidly controlled with intramuscular epinephrine, intravenous corticosteroids, and antihistamines combined with rehydration. The patient was taking nebivolol, which was temporarily withdrawn. She had previously experienced oral allergy syndrome with peach, but no systemic signs. The skin prick test performed 3 weeks after the reaction was positive for whole wheat extract (diameter, $7 \mathrm{~mm}$ ), but negative for gliadin and lipid transfer protein. Serum IgE was positive for wheat flour, hazelnut, carrot, peach, and apple. The molecular diagnosis showed positive results for Tri a $14(3.5 \mathrm{kU} / \mathrm{L})$, nTri a aA_TI ( $\alpha$-amylase) (3.0 kU/L), Mal d $1(0.5 \mathrm{kU} / \mathrm{L})$, Pru p $1(0 . \overline{3} \mathrm{kU} / \mathrm{L})$, Api g 1 $(0.2 \mathrm{kU} / \mathrm{L})$, Cor a $1(0.5 \mathrm{kU} / \mathrm{L})$, and Ara h $8(0.5 \mathrm{KU} / \mathrm{L})$. The results for Cor a 8, Ara h 9, and Pru p 3 were negative. No specific IgE against Tri a 19 ( $\omega-5$ gliadin) was detected. The patient was provided with detailed information, including a strict avoidance diet, in order to prevent further episodes.

Celiac disease is a gluten-induced immune-mediated condition characterized by a specific genotype (HLA-DQ2 and HLA-DQ8) and production of tissue-specific autoantibodies (transglutaminase and endomysium). The inflammatory process targets the intestinal mucosa, although various nonspecific symptoms may also be present, suggesting the systemic nature of the disease [4]. We report 2 cases of an exceptional association between celiac disease and a documented IgE-mediated allergic disease that resulted in anaphylaxis. A similar case has been reported in the literature, although the diagnosis was not based on molecular data [5]. The relationship between allergy and autoimmune disorders is complex and poorly understood, especially in wheat allergy and celiac disease, although some hypotheses can be put forward [6].

Kreiner et al [7] identified shared susceptibility loci and similarities in pathways between allergy and autoimmune diseases, suggesting partially shared mechanisms. IgE autoantibodies have been known to be present in patients with autoimmune disease for more than 40 years, although autoantibodies are not associated with a higher rate of atopy. Nevertheless, IgE was recently suggested to be an active trigger of autoimmunity through mechanisms involving the secretion of type-I interferons by plasmacytoid dendritic cells, recruitment of basophils to lymph nodes, and activation of adaptive immune responses through $\mathrm{B}$ and $\mathrm{T}$ cells. There is also evidence supporting the role of $\mathrm{IgE}$ receptors in dendritic cell function. The activation of these cells by the immune complexes of DNA-specific IgE antibodies can also induce B-cell differentiation and plasma cell formation [8]. The involvement of B cells has also been hypothesized. $\mathrm{CD}^{+}$ $\mathrm{B}$ cells can have a negative regulatory function, and their deficiency can worsen both allergic and autoimmune diseases (such as experimental autoimmune encephalomyelitis, chronic colitis, and lupus-like models of autoimmunity) [9].

In conclusion, the 2 cases we describe support the possible coexistence of autoimmune and IgE-mediated diseases. The presence of IgE specific for Tri a 14, gluten, gliadin, and $\omega-5$ gliadin should be considered a diagnostic marker in patients with confirmed celiac disease who experience anaphylaxis [10] after ingestion of food containing wheat. It is reasonable to hypothesize that the occasional consumption of wheat flourcontaining proteins could trigger IgE-mediated sensitization overlapping with a pre-existing autoimmune disease.

\section{Funding}

The authors declare that no funding was received for the present study.

\section{Conflicts of Interest}

The authors declare that they have no conflicts of interest.

\section{References}

1. Longo G, Berti I, Burks AW, Krauss B, Barbi E. IgE-mediated food allergy in children. Lancet. 2013;382:1656-64.

2. Nilsson N, Sjölander S, Baar A, Berthold M, Pahr S, Vrtala S, et al. Wheat allergy in children evaluated with challenge and IgE antibodies to wheat components. Pediatr Allergy Immunol. 2015;26:119-25.

3. Sander I, Rihs H-P, Doekes G, Quirce S, Krop E, Rozynek P et al. Component-resolved diagnosis of baker's allergy based on specific lgE to recombinant wheat flour proteins. J Allergy Clin Immunol. 2015;135:1529-37.

4. Leonard MM, Sapone A, Catassi C, Fasano A. Celiac Disease and Nonceliac Gluten Sensitivity: A Review. JAMA. 2017;318:647-56. 
5. Borghini R, Donato G, Marino M, Casale R, Tola MD, Picarelli A. In extremis diagnosis of celiac disease and concomitant wheat allergy. Turk J Gastroenterol. 2018;29:515-7.

6. Torres JA, Sastre J, de las Heras M, Cuesta J, Lombardero M, Ledesma A IgE-mediated cereal allergy and latent celiac disease. J Invest Allergol Clin Immunol. 2008;18:407-14

7. Kreiner E, Waage J, Standl M, Brix S, Pers TH, Alves AC, et al. Shared genetic variants suggest common pathways in allergy and autoimmune diseases. J Allergy Clin Immunol. 2017;140:771-81.

8. Ettinger R, Karnell JL, Henault J, Panda SK, Riggs JM, Kolbeck R, et al. Pathogenic mechanisms of IgE-mediated inflammation in self-destructive autoimmune responses. Autoimmunity. 2017; 50:25-36.

9. Noh G, Lee JH. Regulatory B cells and allergic diseases. Allergy Asthma Immunol Res. 2011;3:168-77.

10. Kennard B. Thomas L, Rutkowski I, Azzu K, Yong PFK, Kastemow B, et al. A multicenter evaluation of diagnosis and management of omega 5-gliadin allergy (also known as wheat-dependent exercise induced anaphylaxis) in 132 adults. J Allergy Clin Immunolol Pract. 2018;6:1892-7.

Manuscript received March 11, 2019; accepted for publication May 31, 2019

Giovanni Passalacqua Associate Professor Allergy and Respiratory Diseases Policlinico San Martino - University of Genoa Pad. Maragliano - L.go R Benzi 10 16133 Genoa, Italy E-mail: passalacqua@unige.it 